\title{
TEMPERATURE LOOP STRUCTURE WITH FUZZY AND Classical Controllers
}

\author{
BeRK, P.; RAKUn, J.; Vindis, P.; STAJnKO, D. \& LAKOTA, M.
}

Abstract: The use of fuzzy logic controller approach against the classical controller has reached the highest degree in engineering management and control. In our applications we decided for the synthesis of fuzzy logic PID and classical PID temperature controller and realization of the control loop structure. The synthesis of fuzzy and classical temperature controller was realized with the HP laptop 6830s Compaque NA779ES, software Matlab/Simulink 2008b and FIS (Fuzzy Inference System) soft logical tool. By using the simulation program Matlab/Simulink/FIS we simulate the operation of fuzzy and classical controller in the temperature regulating cycle with the process of the first and second order and implements disorder (square function) and made a comparison between fuzzy and classical controller functioning. In statistical analysis we concluded that the error of fuzzy PID controller in the control cycle with second-order process and implements disorder was zero. The use of fuzzy temperature controller can reduce power consumption by $25 \%$.

Key words: controller, fuzzy logic, synthesis, transfer function
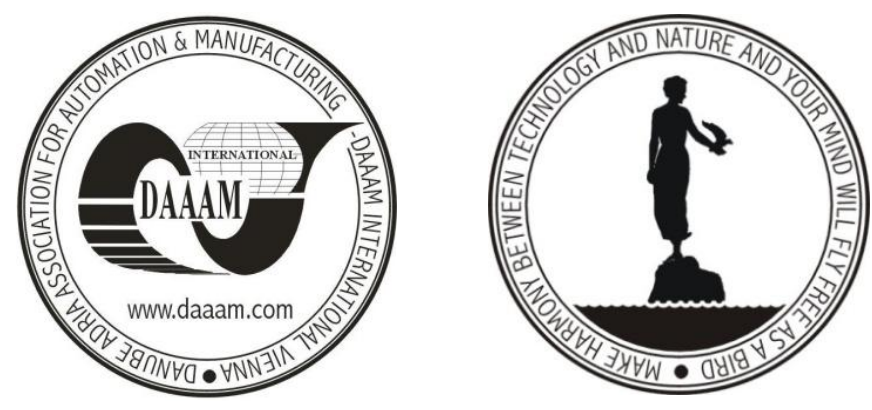

Authors' data: Bs. Elect. Eng. Berk, P[eter]; Dr. Rakun, J[urij]; Dr. Vindis, P[eter]; Assoc. Prof. Stajnko, D[enis], Assoc. Prof. Lakota, M[iran], University of Maribor, Faculty of Agriculture and Life Sciences, Pivola 10, SI-2311, Hoce, Slovenia, peter.berk@uni-mb.si,_ jurij.rakun@uni-mb.si, denis.stajnko@uni-mb.si,miran.lakota@uni-mb.si

This Publication has to be referred as: Berk, P[eter]; Rakun, J[urij]; Vindis, P[eter]; Stajnko, D[enis] \& Lakota, M[iran] (2010). Temperature Loop Structure with Fuzzy and Classical Controllers, Chapter 13 in DAAAM International Scientific Book 2010, pp. 117-128, B. Katalinic (Ed.), Published by DAAAM International, ISBN 978-3-901509-74-2, ISSN 1726-9687, Vienna, Austria

DOI: $10.2507 /$ daaam.scibook.2010.13 
Berk, P.; Rakun, J.; Vindis, P.; Stajnko, D. \& Lakota, M.: Temperature Loop Struct...

\section{Introduction}

In the control technique complex dynamic systems (Dzonlagic, 1995) are very often faced the process with the nonlinear dynamic characteristic. Therefore, such a process is difficult to determine in the model, since it can be inaccurate and therefore useless (Dzonlagic, 1995). Controlling these problematic processes take place mainly on the basis of human experience and its direct intervention in the process. Fuzzy controllers are able to summarize human knowledge of the system and introduce them to the laws of control. This is possible by solving management problems, without creating a precise model required by classical control engineering. This is the reason that the use of fuzzy logic took hold mainly in control engineering.

The use of fuzzy logic in industrial applications is increasing in the recent years. Japanese industry has launched an aggressive marketing of fuzzy ideas in the form of the first commercial outputs (Virant, 1998). In the field of automation technology we meet the following major areas of application, summarized in the next indent.

- EB thermostat for electrical floor heating with built-in microprocessor and fuzzy logic, by external inputs, adjust the thermostat operation. Fuzzy logic prevents the fluctuation of temperature in space and thus reduces power consumption (Figure $1)$.



Fig. 1. Thermostat for electrical floor heating

- Canadian company NPH (National Plastic Sensor heater) offers in the global market a temperature control with fuzzy logic to provide precise control of temperature processes. In the case where the control module (fuzzy controller) detects a failure in the process, the decision fuzzy logic process returns to a stable state (Figure 2).

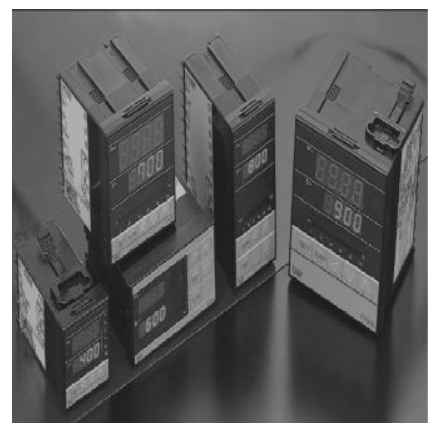

Fig. 2. Fuzzy temperature controller 
- There are intelligent fuzzy controllers (Fuzzy Logic Control; FLC), which are designed to regulate the temperature of steam in thermal power plants. Temperature control is the most demanding process control loop for steam. The results showed that the FLC gives better results than conventional proportionintegral-differential (PID) controller. The main advantages are the reduction of overshoot and stricter regulation of steam temperature. FLC controllers have a very good result for complex nonlinear dynamic processes.

- In the Japanese town of Sendai a Metro operates guided by the principle of fuzzy technology from 1987 (Dzonlagic, 1995). The system was conducted more comfortable and economical for guiding than if performed by an experienced train driver.

- Managing elevators with fuzzy logic significantly reduced waiting times of arrival of the elevator to transport people in the skyscraper (Dzonlagic, 1995). In this area, most Japanese firms are using control system based on a computer equipped with the steering components of fuzzy logic.

- Temperature controller on the principle of fuzzy logic provides significantly better performance compared to the usual classical PID controller (Dzonlagic, 1995).

The use of fuzzy logic spread in Japan and around the world very well to other areas of automation (transportation systems, robots, process industry, automotive industry, ecology etc.). The number of applications in other areas (consumer electronics, economics, trade, tourism and catering) is also extremely fast growing.

\section{Design fuzzy PID and classical PID controller through software and hardware components}

By using graphical tools in Simulink of Matlab subsystem, we first designed a model temperature of the process through the classical PID controller (Standeker, 1993). The model temperature process represented the transfer function of the first and second order and implemented disorder (Figure 3). Following the successful design a simulation process to we proceeded regulate the temperature of the first and second order. With the help of configuration parameters (proportional gain, differential gain, integral gain, integrating time, and differential time) we optimize the option to set the classical controlling system (classical PID controller). Following the successful design of classical control systems, we started the program package MATLAB/Simulink/FIS in the design of fuzzy PID controller, with the same process as a model for classical control system (Figure 3). If the quality of fuzzy regulation was not sufficient to meet our requirements, we repeat the design of the regulator as long, until we achieve the desired results. Simulations of fuzzy and classical regulators were held on a laptop. 


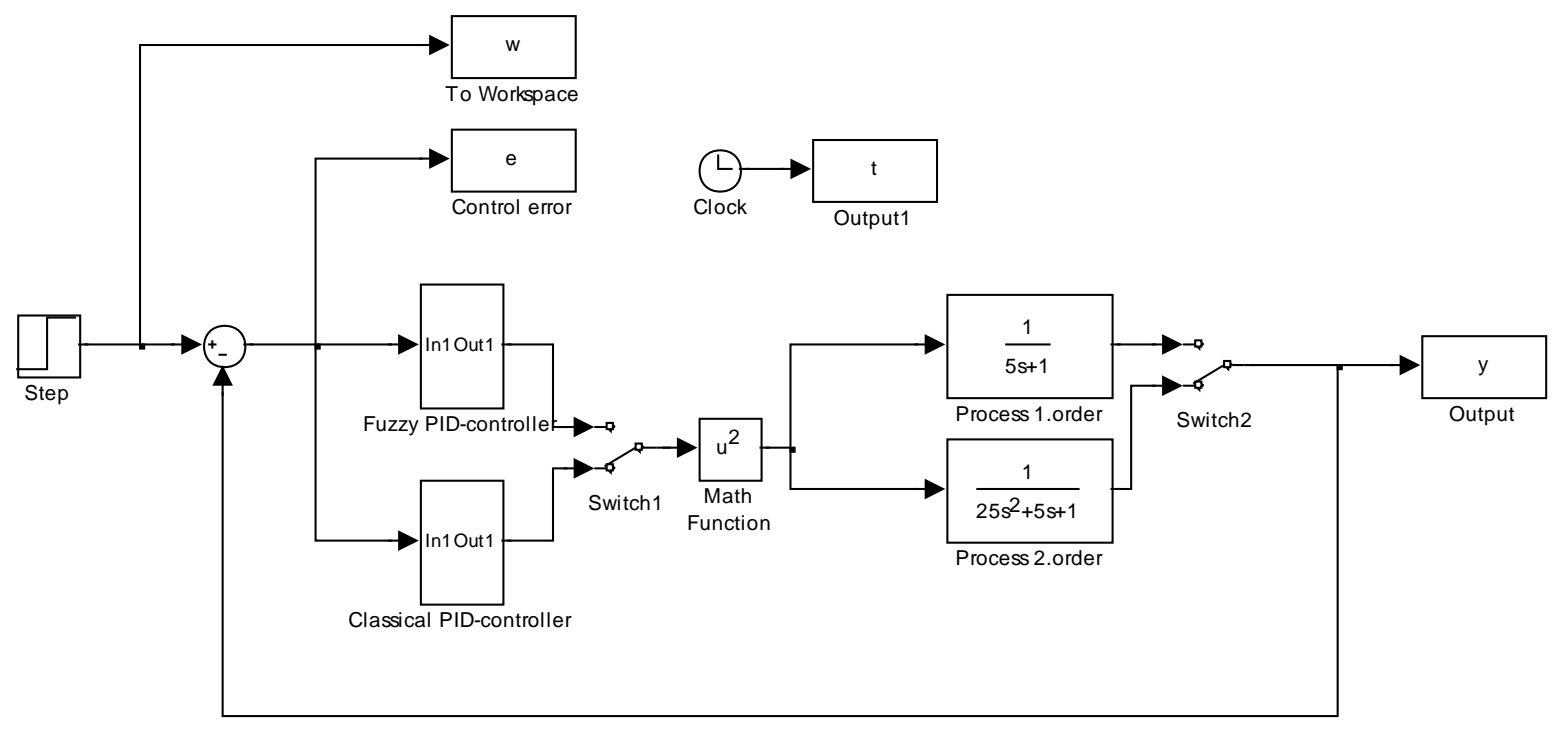

Fig. 3. A model of temperature process with fuzzy PID and classical PID controller and implemented disorder using the program Matlab/Simulink/FIS

\subsection{Hardware}

A hardware control cycle consists of the HP Compaq 6830s Notebook NA779ES. A HP 6830s Laptop has a 3 GB DDR2 $800 \mathrm{MHz}$ memory, expandable to 8 GB. Hard Drive has capacity of 320 GB, supports SMART SATA bus communicates and operates plants in 5400 in a minute.

\subsection{Software Matlab/Simulink 2008b}

Matlab is a software package designed to numerical calculations, such as arithmetic operations vectors, difference equations and presentation of results. For such extensive use Matlab has got available libraries, through which we can come to more knowledge in the areas of regulation (classical, discrete, fuzzy) and designing filters. By entering commands in Matlab's workspace the programmer can directly input command through the command line in the command window or it can be commanded by entering into a separate file with the extension *.m. By recording command in the Command window or in a file the implementation can be repeated without re-entering. Matlab's functions are easily completed by a user through the Matlab programming language. The basic program structure is a matrix. In the Matlab program it is necessary to define variables and to reserve space in a memory. Effective programming in Matlab is achieved by pre-booking of memory and using commands with a dot (operate on the matrix components) and avoid use for loops.

Simulink is a graphical upgrade ofMatlab 2008b. It is used for modelling and simulation of mathematical models. Models can be assembled with available blocks, so a detailed knowledge of Matlab commands is not required. Collections blocks, which were used for the synthesis of the fuzzy and classical regulator, can be found under the directory in Simulink. It allows us a simple graphical representation of simulation results. It can be run in Matlab environment by using Simulink, or through the icons in Matlab Toolbar. 


\subsection{Fuzzy logic tool FIS}

A fuzzy PID controller was planned with the help of fuzzy logical tools FIS. For the construction, editing and monitoring Fuzzy systems there are five basic tools, as shown in Figure 4 and are represented by the following indents:

- Editor to determine the inferential fuzzy system FIS (FIS Editor),

- Membership functions editor,

- Rule editor,

- Rule viewer and

- Surface viewer.

Fig. 4. The basic tools in the FIS

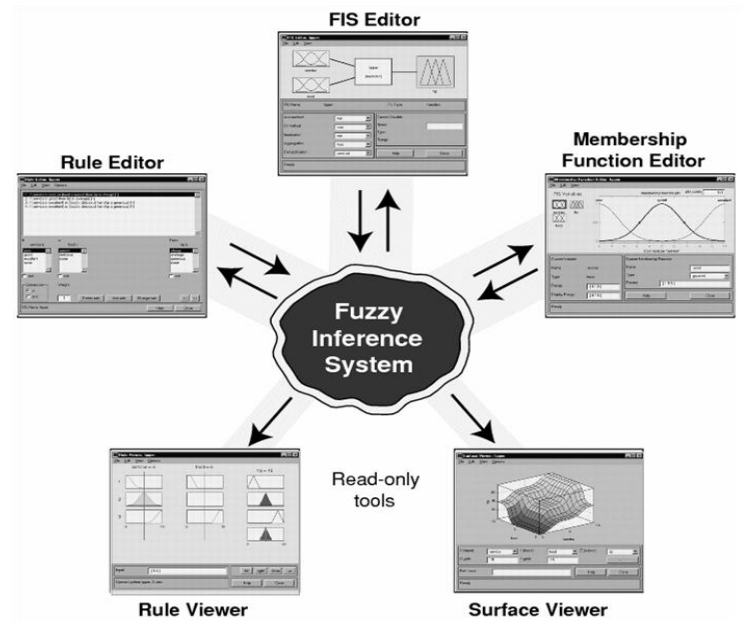

All the basic tools are dynamically linked in the FIS. Any changes in the parameters (membership functions of input and output variables of the regulator) which can be configured in the FIS, affect on the accuracy and stability of fuzzy controller. In the membership functions editor we defined their shape (triangular, trapezoidal, rectangular ...). We used the rule editor to edit the list of rules by which we determined the response of fuzzy control system. A rule viewer shows Matlab's technical tool, which show diagrams of fuzzy membership functions in the operating point. The surface viewer is used for diagnosis active rules and how each form of membership functions affects the final calculation of the output value of the variable fuzzy regulator. With the help of surface viewer area shows a characteristic output of the fuzzy regulator variables, which depend on different sets of input variables of the regulator.

\section{Fuzzy PID controller (methods)}

By comparing the classical and fuzzy PID controller which model was performed using Matlab and its subsystems (Simulink, FIS)we want to show the step response of these two controllers, when in the process appears the Disorder which we illustrate through quadratic function(Figure 3). We conducted synthesis (simulation) of fuzzy PID controller with two input linguistic variables (E; control error, DE; outflow regulating tolerance) and one output linguistic variable (Y; heaters power in watts). 
Berk, P.; Rakun, J.; Vindis, P.; Stajnko, D. \& Lakota, M.: Temperature Loop Struct...

In this case we have to chose a form of membership functions for the fuzzy PID controller in the first method (softening) of planning a process choose a simple shape membership functions (triangular, trapezoidal, ...) as a input and output linguistic variables. In the second procedure (inference), we designed an appropriate fuzzy rule written in a matrix form. Through the third procedure (walls) we calculated the sharp, applied greatness in control technology, which can be controlled by an executive body (heating device). After completing the design of fuzzy controller in the basic structure of the temperature control cycle a simulation operation of fuzzy logic system was designed and a comparative analysis among classical regulators. During out of simulations response was drawn on a laptop screen which shows comparison between fuzzy and classical controller. In case of unsatisfactory results, we changed the system of fuzzy membership functions and write new rules in a matrix form, and change the gain factor $\left(\mathrm{K}_{\mathrm{p}}\right.$; proportional gain, $\mathrm{K}_{\mathrm{d}}$; differential gain, $\mathrm{K}_{\mathrm{i}}$; integral gain)and temporal variables $\left(\mathrm{T}_{\mathrm{d}}\right.$; differential time).

\subsection{Modelling of closed-loop process with fuzzy PID controller through FIS and Simulink tools}

The fuzzy PID controller designed by using of Simulink tools FIS (Figure 5) can be treated as a regulator of the nonlinear static characteristic and the proportional gain, differential gain and integral gain. Terms nonlinearity is dependent on fuzzy PID controller of the rule base and membership functions of input (E, DE) and output linguistic variables $(\mathrm{Y})$.

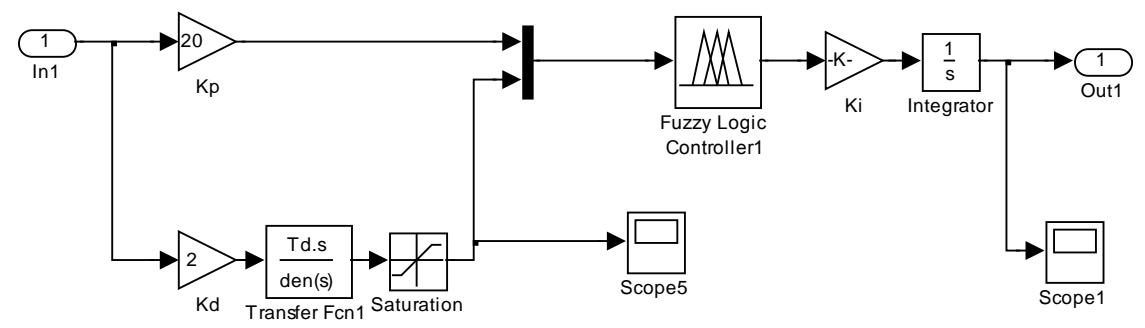

Fig. 5. Fuzzy PID controller designed using Simulink tools

We are illustrating the simple case of temperature regulation in the building. For this purposes we have modelled in the programming tool Matlab/Simulink 2008b a simple closed-loop of temperature control loop with the associated transfer function, fuzzy PID controller (Figure 10) and a model with incorporating quadratic function (Figure 11). In this model transfer function represented the temperature process of the first and second order, we therefore normalized control error in ${ }^{\circ} \mathrm{C}$ (example; $-20^{\circ}$ to $20^{\circ} \mathrm{C}$ ) and recorded them with two equations:

- The equation of the first order transfer function lasts:

$$
F(s)=\frac{1}{5 s+1}
$$

- The equation of second-order transfer function lasts: 


$$
\mathrm{F}(\mathrm{s})=\frac{1}{25 \mathrm{~s}^{2}+5 \mathrm{~s}+1}
$$

Where:

$\mathrm{F}(\mathrm{s}) \quad$ - Transfer function

s - Operator

The optimizing of fuzzy controller started with the process of softening of the two inputs and one output linguistic variables. The first entry in the fuzzy controller is represented linguistic variable $\mathrm{E}$, which is written with the equation:

$$
\mathrm{E}=\mathrm{K}_{\mathrm{p}} \cdot(\mathrm{W}-\mathrm{X})
$$

Where:

E - Control error (in the fuzzy controller input)

W - Desired value of controlled variable

$\mathrm{X}$ - Actual (measured) value of controlled variable

$\mathrm{K}_{\mathrm{p}} \quad$ - Proportional gain

The other input in the fuzzy controller represented linguistic variable DE, which was written by the equation:

$$
\mathrm{DE}=\mathrm{K}_{\mathrm{d}} \cdot \frac{\mathrm{dE}}{\mathrm{dt}}
$$

Where:

DE - Time derivative of regulating tolerance

E - Control error

$\mathrm{t} \quad$ - Time

$\mathrm{K}_{\mathrm{d}} \quad$ - Differential gain

PID fuzzy controller model in Figure 5 is similar to the model of fuzzy PD controller (Dzonlagic, 1995). Both models differ only in the definition of output fuzzy variables in the case of PD controller here is differential output (DY), which is written by the equation:

$$
\mathrm{DY}=\mathrm{K}_{\mathrm{d}} \cdot \mathrm{DE}+\mathrm{K}_{\mathrm{p}} \cdot \mathrm{E}
$$

Where:

DY - differential output

$\mathrm{K}_{\mathrm{d}}$ - differential gain

DE - Time derivative of regulating tolerance

$\mathrm{K}_{\mathrm{p}} \quad$ - Proportional gain

E - Control error 
Berk, P.; Rakun, J.; Vindis, P.; Stajnko, D. \& Lakota, M.: Temperature Loop Struct...

The output (Y) of fuzzy PID controller we received by entering additional dynamic Article (integrator).

Three linguistic variables (E, DE and Y) were described with FIS tools by five membership functions triangular (Figure 6 and 7). All membership functions were presented with linguistic values described in Table 1.

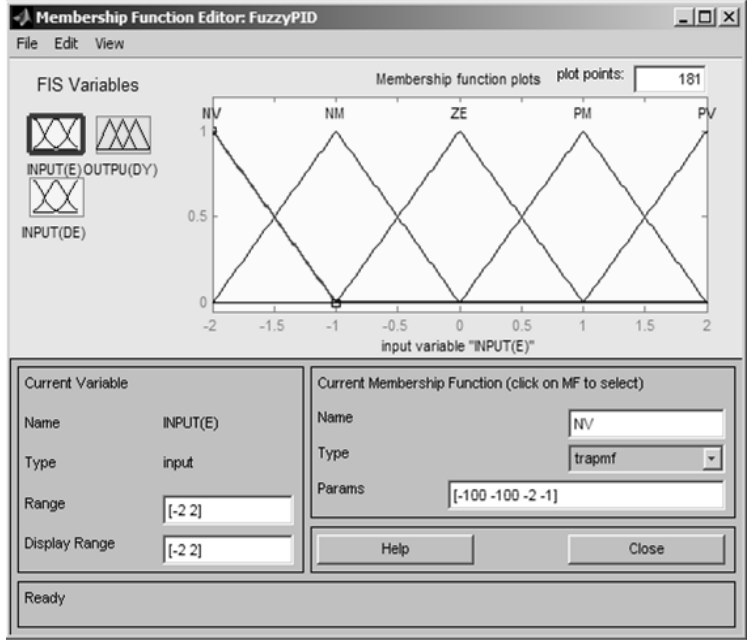

Fig. 6. Membership functions of linguistic Fig. 7. Membership functions of variables $\mathrm{E}$ and $\mathrm{DE}$

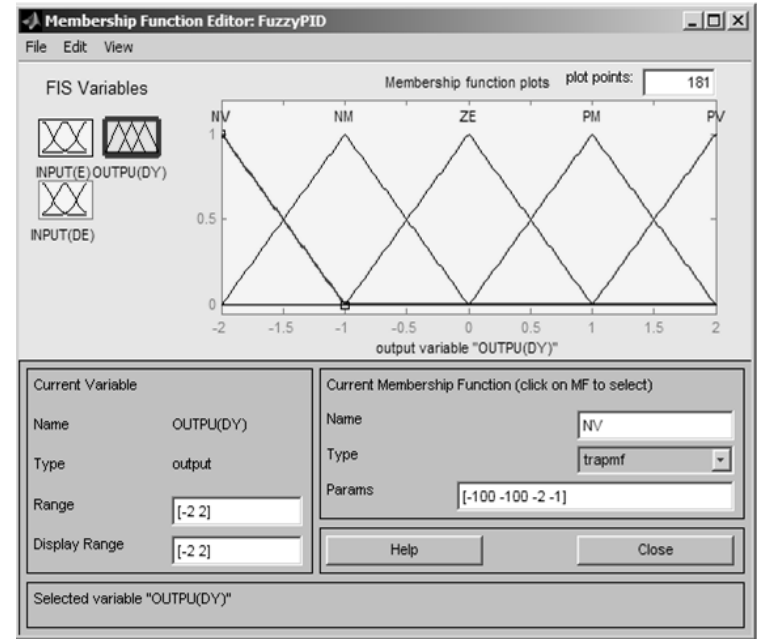

linguistic variable $\mathrm{Y}$

\begin{tabular}{|c|l|}
\hline $\begin{array}{c}\text { Linguistic value } \\
\text { (label in the FIS) }\end{array}$ & $\begin{array}{c}\text { The rate of linguistic values } \\
\text { (describe in words) }\end{array}$ \\
\hline NV & Negative high \\
\hline NM & Negative little \\
\hline ZE & Nothing \\
\hline PM & Positive little \\
\hline PV & Positive many \\
\hline
\end{tabular}

* The rate of linguistic values ranged between 0 and 1

Tab. 1. Description of the degree of linguistic value membership functions PID fuzzy controller

After completing the process of softening of the two inputs and one output linguistic variable we continued with the inference process (decision making). The procedure was performed so that we write a set of rules in a matrix format (Figure 8).

\begin{tabular}{|c|c|c|c|c|c|c|}
\hline \multirow{2}{*}{\multicolumn{2}{|c|}{ OUTPUT (Y) }} & \multicolumn{5}{|c|}{ INPUT (E) } \\
\hline & & NV & NM & ZE & $\mathbf{P M}$ & PV \\
\hline \multirow{5}{*}{$\begin{array}{c}\text { INPUT } \\
\text { (DE) }\end{array}$} & NV & NV & NV & NV & NM & $\mathrm{ZE}$ \\
\hline & NM & $\mathrm{NV}$ & $\mathrm{NV}$ & NM & $\mathrm{ZE}$ & $\mathrm{PM}$ \\
\hline & $\mathbf{Z E}$ & NV & NM & ZE & PM & PV \\
\hline & $\mathbf{P}$ & $\mathrm{NM}$ & $\mathrm{ZE}$ & PM & PM & PV \\
\hline & & & $\mathrm{M}$ & PV & PV & \\
\hline
\end{tabular}

Fig. 8 . The set of rules in a matrix format 
The importance of linguistic value rates are shown in the Table 1 . We have made language description of the system (fuzzy PID controller) with shape rules "IFTHEN". We developed 25 rules (Table 1), which we have entered into the tool FIS (Rule Editor, Figure 4).

In the language of controllers for the first rule the logical sentence means: if the desired value differs significantly from the measured value (room temperature) and the difference between the two temperature further declines then the control action must be high (maximum power heating appliances).

After the establishment of control rules in the matrix form, we designed a fuzzy control algorithm, called the inference. Inference was designed from the rules of control by the use of inference operators. With the help of inference rules we established in the crowd (Figure 8), fuzzy output crowd. In the application we used Mamdani inference operator (Dzonlagic, 1995), with whom we have formed membership functions sets of rules (all rules), based on output. We set the Mamdani inference operator in the tool FIS. Then process of Focus followed where we choose the most used method in practice and contribute the best results. This method is called in the controller technique: method (COG) (Dzonlagic, 1995) and we set it in the tool FIS. The method allows calculation of the sharp value, which is often applied in the control engineering and can control enforcement articles (heater).

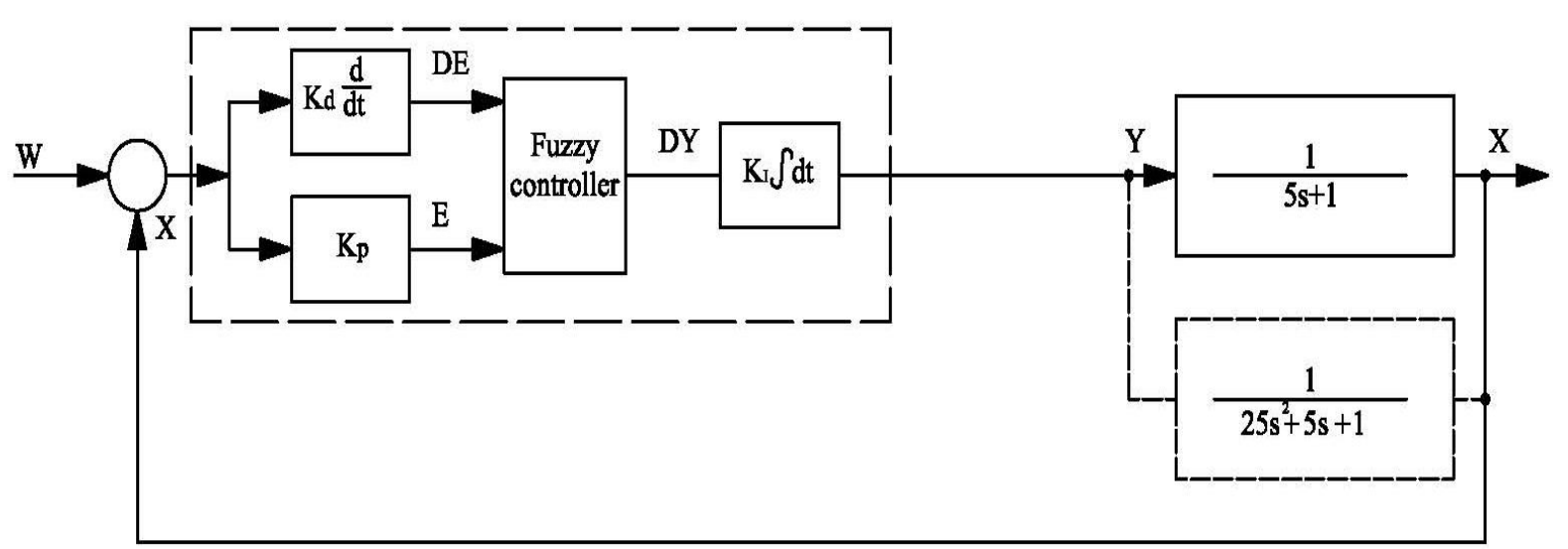

Fig. 10. Model of the closed-loop process control loop of the first and second order with fuzzy PID controller

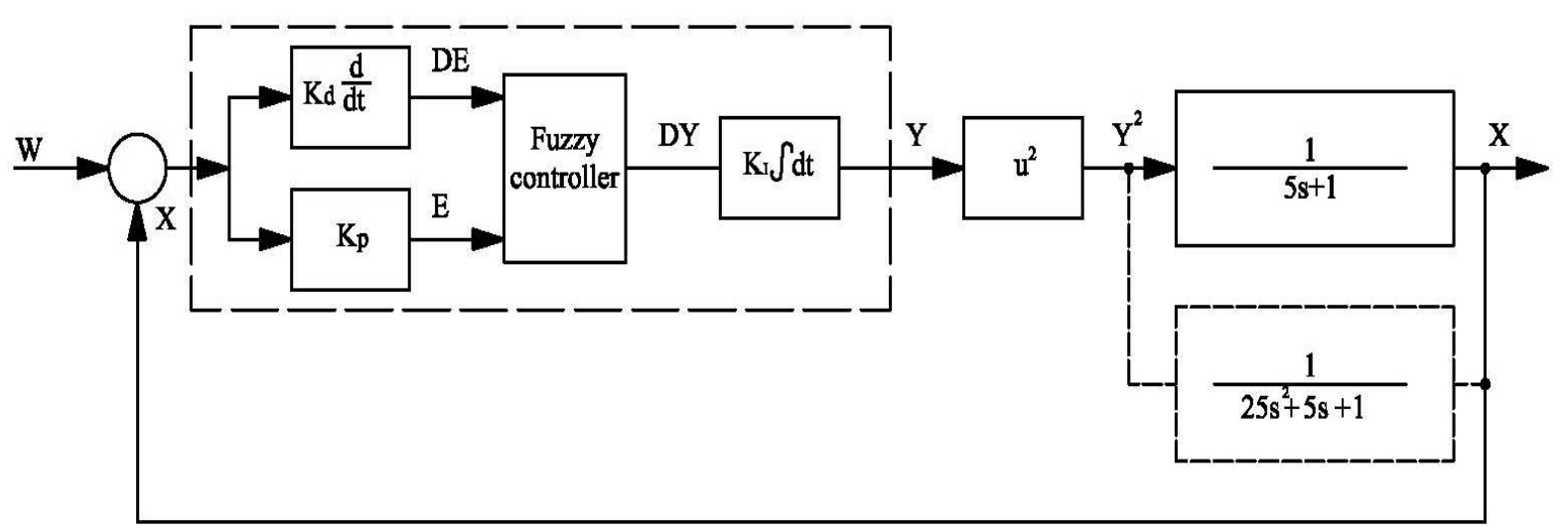

Fig. 11. Model of the closed-loop process control loop of the first and second order with fuzzy PID controller and implements disorder 
Berk, P.; Rakun, J.; Vindis, P.; Stajnko, D. \& Lakota, M.: Temperature Loop Struct...

After completion of the operations (softening, inference, Focus) we finished the design of fuzzy PID controller. We carried out optimization of fuzzy PID controller, so we adjusted the stability, robustness, quality of regulation and changes variables ( $\mathrm{K}_{\mathrm{p}}$; proportional gain, $\mathrm{K}_{\mathrm{d}}$; differential gain, $\mathrm{K}_{\mathrm{i}}$; integral gain). Assessment of discrepancies between fuzzy PID and classical PID controller was done by determining a visually effective method in the program Matlab.

\section{Results}

The results represent a correlation analysis between the fuzzy PID and classical PID controller in temperature controller cycle with the transfer function of the first and second order and incorporating disorder. Graph (Figure 12) shows the step response (normalized temperature: $20{ }^{\circ} \mathrm{C}$ ) of fuzzy controller for the control loop with the corresponding transfer function of the first order, where the proportional gain equal; $K_{p}=20$, differential gain; $K_{d}=2$, integral gain; $K_{i}=0.01$, differential time; $T_{d}=1$ and integral time; $T_{i}=10$. Another example given by the graph(Figure 13) shows the step response of the fuzzy controller in temperature controller cycle with the first order transfer function, where we have in the additional control loop implemented disorder. Graphs (Figure 14, 15, 16 and 17) show the remaining cases, which represent the step responses of the fuzzy and classical controller for temperature control loop with second-order transfer function and incorporating disorder.

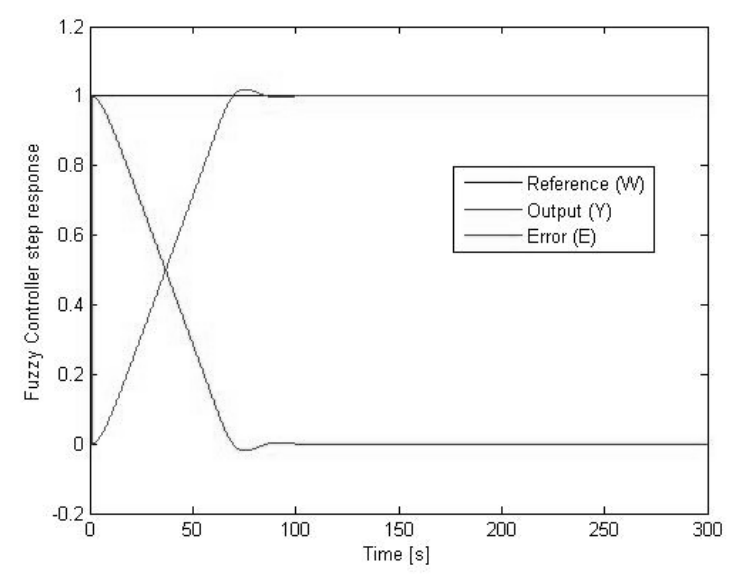

Fig. 12. Response of fuzzy PID controller on step without incorporating disturbance (Figure 10), order process 1

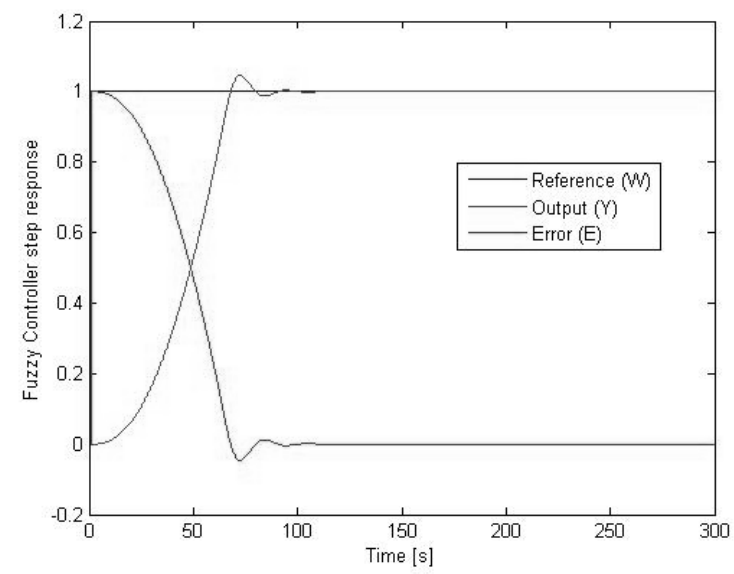

Fig. 13. Response of fuzzy PID controller on step with incorporating disturbance (Figure 11), order process 1 


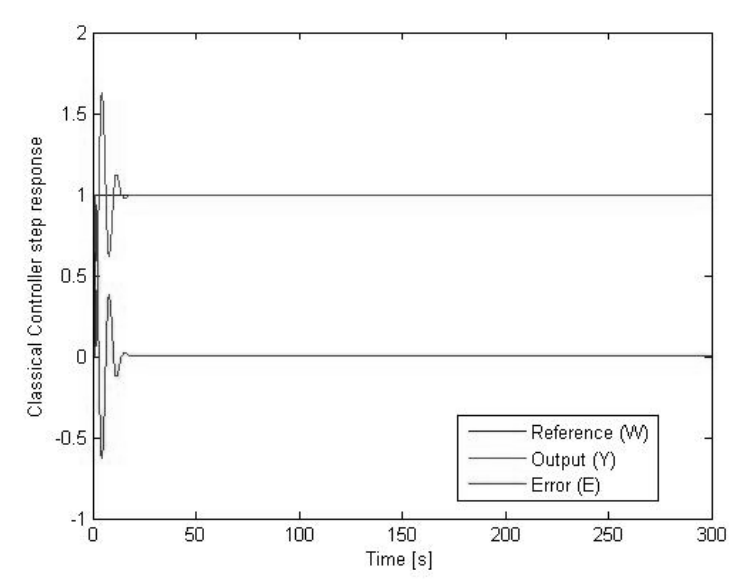

Fig. 14. Response of classical PID controller on step without incorporating disturbance (Figure 3), order process 2

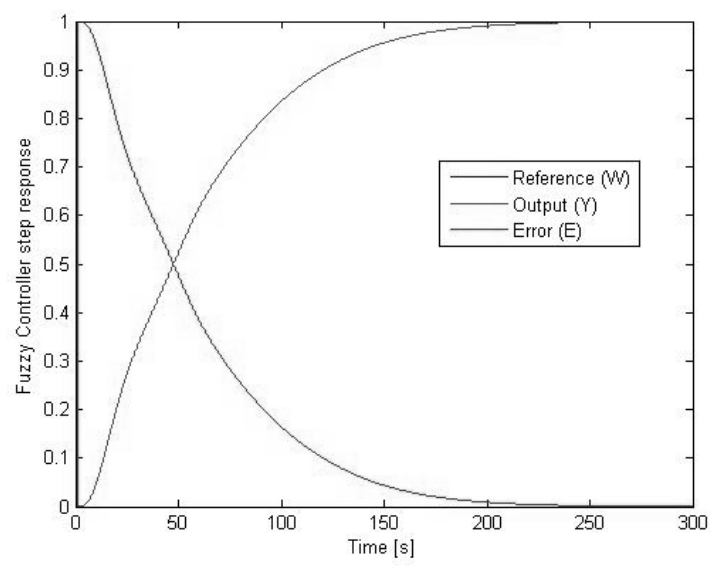

Fig. 16. Response of fuzzy PID controller on step without incorporating disturbance (Figure 10), order process 2 , $\mathrm{K}_{\mathrm{p}}=2$

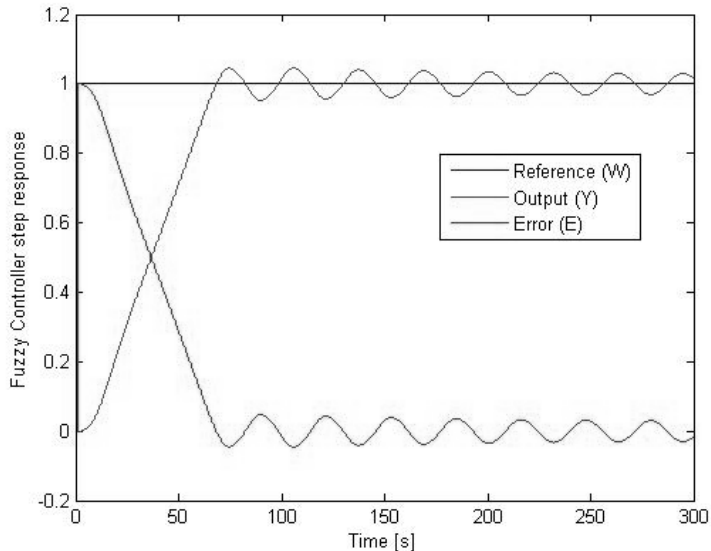

Fig. 15. Response of fuzzy PID controller on step without incorporating disturbance (Figure 10), order process 2 , $\mathrm{K}_{\mathrm{p}}=20$

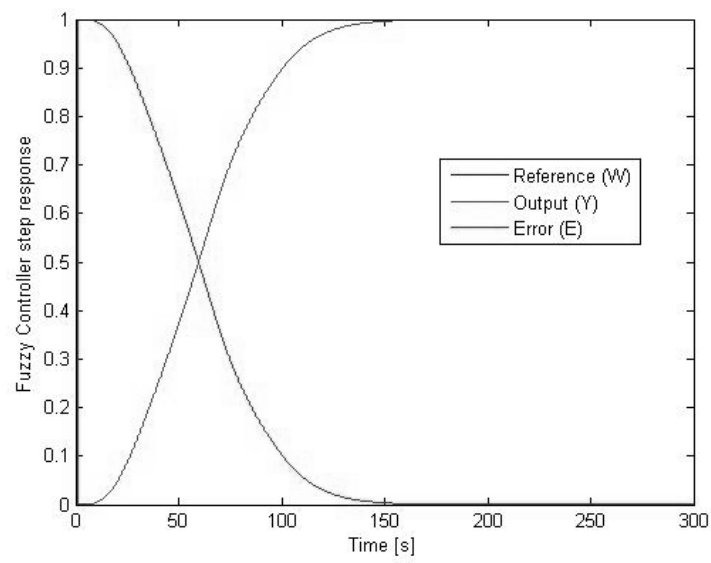

Fig. 17. Response of fuzzy PID controller on step with incorporating disturbance (Figure 10), order process 2 , $\mathrm{K}_{\mathrm{p}}=2, \mathrm{~K}_{\mathrm{i}}=0.01$

By combining the properties of $\mathrm{P}, \mathrm{D}$ and I dynamic articles was designed the controller PID (Standeker, 1993) characterized by a high speed, accuracy and stability of the system. From the responses to the step of fuzzy controller for firstorder process Figure 12 shows that the actual value of the controlled variable takes the value one. Fuzzy controller does not allow controlling derogation, which is also inappropriate for fuzzy control cycle with incorporating disturbance (Figure 13).

In graphical responses (Figure 14 and 16) a fuzzy and the classical controller in the case of second-order process after a transitional phenomenon actual controlled variable is stabilized at the value one. This means that fuzzy and classical controllers in the case of temperature process, does not allow control derogation.

For classical control cycle with classical PID controller and incorporating disturbance in the process of second-order control cycle becomes unstable (infinite 
Berk, P.; Rakun, J.; Vindis, P.; Stajnko, D. \& Lakota, M.: Temperature Loop Struct...

value of the actual controlled variable). In fuzzy control cycle with fuzzy PID controller and incorporating disturbance in the process of second-order the control cycle is stable and at certain predetermined parameters (integral gain) a control does not allow deviations (Figure 17).We found that the fuzzy control system suitable in processes where disorder is implemented but we must be careful that we correctly set the parameter controller $\left(\mathrm{K}_{\mathrm{p}}, \mathrm{K}_{\mathrm{i}}\right)$ otherwise obtain a derogation from the reference value. The optimization of linguistic terms change the input variables, membership functions, can we improve the functioning of the fuzzy logic controller.

\section{Conclusions}

The result shows that fuzzy logic controller is useful in applications of nonlinear static characteristic, where classical methods with usually classical PID controllers cannot be a satisfactory outcome. This will be the case with implements disturbance (quadratic function) in the temperature cycle control of second-order transfer function. Fuzzy controller allows the user apply their knowledge of the problem and transfer it to an appropriate system environment, which is close to the human way of thinking (room temperature control). Because this is a more complex task than just inserting a few control parameters we use a special user interface (FIS) for designing fuzzy logic applications. Fuzzy PID controller in a temperature control process applications was proved as a very good choice, because the planning process of fuzzy controller is relatively simple and suitable for engineering practice.

So far, we have made the simulation of fuzzy controller activity in the further we want to do real design process which will be supported by the temperature and humidity sensors, and input and output devices to capture data in this case, we could control climate change in the lounge.

\section{References}

Dzonlagic, D. (1995). Fundamentals of fuzzy control systems design. Faculty of Electrical Engineering and Computer Science of Maribor, ISBN: 86-435-0050$\mathrm{X}$, Maribor

Virant, J. (1998). The fuzzy sistems. Radovljica: Didakta, 1998, ISBN: 961-6214-39$\mathrm{X}$, Radovljica

Standeker, C. (1993). Control and regulation systems part I.: Controlling. Technical publisher of Slovenia, ISBN: 86-365-0104-0, Ljubljana

Standeker, C. (1993). Control and regulation systems part II.: Regulation. Technical publisher of Slovenia, ISBN: 86-365-0115-6, Ljubljana

***http://courses.washington.edu/css457/matlab/learning_matlab.pdf - The

Mathworks, MATLAB student version (2001), Accessed: 2010-05-05

***http://www.caspur.it/risorse/softappl/doc/matlab_help/pdf_doc/fuzzy/fuzzy_tb.pd $\mathrm{f}$ - The Mathworks, User's Guide, Version 2, Accessed: 2010-10-5 